Situs Jurnal : $\underline{\text { http://ejournal.stiepancasetia.ac.id/index.php/iieb }}$

Volume 6 Nomor 3 November 2020

Hal $443-452$

\title{
PENGARUH KECERDASAN EMOSIONAL, KECERDASAN INTELEKTUAL, DAN MOTIVASI TERHADAP KINERJA PERSONIL RESKRIM POLRESTA BANJARMASIN
}

\section{Andik Ariyanto, Titien Agustina*}

\begin{abstract}
The role of the Banjarmasin Police Criminal Investigation Personnel is very important in improving performance, especially in improving service quality. Performance can be influenced by emotional intelligence, intellectual intelligence, and work motivation. To analyze and determine the effect of these variables on performance, it is necessary to conduct research with quantitative methods. The population is all police officers in Reskrim, totaling 60 people. The sampling technique used a census so that the study sample amounted to 60 people. The data collection technique used a questionnaire by providing a list of questions to be filled in by each Banjarmasin Police Reskrim Personnel. Data were analyzed by multiple regression analysis. The results of this study indicate that emotional intelligence, intellectual intelligence, and work motivation have a significant effect on performance partially and collectively. Emotional intelligence, intellectual intelligence, and work motivation of Criminal Investigation personnel must continue to be improved because they affect performance.
\end{abstract}

Keywords: Performance, motional intellegent, intellectual intellegent, and work motivation

Abstrak: Peran Personil Reskrim Polresta Banjarmasin sangat penting di dalam meningkatkan kinerja, khususnya terhadap peningkatan kualitas layanan. Kinerja bisa dipengaruhi oleh kecerdasan emosional, kecerdasan intelektual, dan motivasi kerja. Untuk menganalisis dan mengetahui pengaruh variabel-variabel tersebut terhadap kinerja, perlu dilakukan penelitian dengan metode kuantitatif. Populasi adalah semua anggota polisi di Reskrim berjumlah 60 orang. Teknik pengambilan sampel menggunakan sensus sehingga sampel penelitian berjumlah 60 orang. Teknik pengumpulan data menggunakan kuesioner yaitu dengan cara memberikan daftar pertanyaan untuk diisi oleh setiap Personil Reskrim Polresta Banjarmasin. Data dianalisis dengan analisis regresi berganda. Hasil penelitian ini menunjukkan bahwa kecerdasan emosional, kecerdasan intelektual, dan motivasi kerja berpengaruh signifikan terhadap kinerja secara parsial dan bersama-sama. Kecerdasan emosional, kecerdasan intelektual, dan motivasi kerja Personil Reskrim harus terus ditingkatkan karena berpengaruh pada kinerja.

Kata kunci: Kinerja, kecerdasan emosional, kecerdasan intelektual, dan motivasi kerja 


\section{Latar Belakang}

Kualitas kinerja Polri, salah satunya dapat diketahui dari kualitas pelayanan yang diberikan. Melalui penilaian yang diberikan masyarakat maka citra Polri akan terbentuk sehingga berbagai penilaian positif dan negatif dari masyarakat Indonesia terhadap kinerja Polri akan selalu terdengar di media sosial. Karena baik buruk citra Polri tergantung dari penilaian masyarakat yang dilayani. Apakah masyarakat bersikap Apatis, Reaktif, Kritis atau juga puas atas kinerja Polri yang selama ini telah dilaksanakan. Fungsi kepolisian merupakan salah satu fungsi pemerintahan negara di bidang pemeliharaan keamanan dan ketertiban masyarakat, penegakan hukum, perlindungan, pengayoman, dan pelayanan kepada masyarakat. Keamanan dan ketertiban masyarakat adalah suatu kondisi dinamis masyarakat sebagai salah satu syarat terselenggaranya proses pembangunan nasional dalam rangka tercapainya tujuan nasional yang ditandai oleh terjaminnya keamanan, ketertiban, dan tegaknya hukum, serta terbinanya ketentraman, yang mengandung kemampuan membina serta mengembangkan potensi dan kekuatan masyarakat dalam menangkal, mencegah, dan menanggulangi segala bentuk pelanggaran hukum dan bentuk-bentuk gangguan lainnya yang dapat meresahkan masyarakat.

Perkembangan kemajuan masyarakat yang cukup pesat, seiring dengan merebaknya fenomena supremasi hukum, hak asasi manusia, globalisasi, demokratisasi, desentralisasi, transparansi, dan akuntabilitas, telah melahirkan berbagai paradigma baru dalam melihat tujuan, tugas, fungsi, wewenang dan tanggung jawab Kepolisian Negara Republik Indonesia yang selanjutnya menyebabkan pula tumbuhnya berbagai tuntutan dan harapan masyarakat terhadap pelaksanaan tugas Kepolisian Negara Republik Indonesia yang makin meningkat dan lebih berorientasi kepada masyarakat yang dilayaninya.

Salah satu tugas berat yang diemban kepolisan adalah melakukan penyelidikan, penyidikan, dan pengawasan penyidikan oleh penyidik Pegawai Negeri Sipil (PPNS). Tugas ini dikerjakan bagian reskrim kepolisian. Tugas pokok reserse Polri adalah melaksanakan penyelidikan, penyidikan, dan koordinasi serta pengawasan terhadap Penyidik Pegawai Negeri Sipil (PPNS) berdasarkan Undangundang nomor 8 tahun 1981 tentang Kitab Undang-undang Hukum Acara Pidana dan peraturan dan perundangan. Kinerja personil reskrim kepolisan sangat erat kaitannya dengan kecerdasan emosi karena pekerjaan penyelidikan, penyidikan, dan pengawasan memerlukan ketenangan dan kestabilan emosi yang baik.

Personil reskrim kepolisian harus memiliki karakteristik personal yang kuat (Agustina, 2019); (Agustina, Gerhana, \& , 2020) diantaranya adalah locus of control, self efficacy, motivasi, juga kecerdasan emosional yang baik di dalam memberikan kontribusi terhadap keberhasilan kerjanya (M Anwar, 2017); (Wahab, Anwar, \& Yasrie, 2018); (Mahfuzil Anwar, Chandrarin, Darsono, \& Respati, 2017). Jika personil tidak dapat menahan kendali emosionalnya akan mengalami pertarungan batin yang merusak kemampuannya untuk memusatkan perhatian pada tugas-tugas dan memiliki pikiran yang jernih. Kecerdasan emosional yang ditandai oleh kemampuan pengenalan diri, pengendalian diri, motivasi diri, empati dan kemampuan sosial akan mempengaruhi perilaku seseorang yang nantinya juga mempengaruhi kinerja personil (Prawitasari, 2016); (Pratama \& Suhaeni, 2018); (Ardiansyah \& Sulistiyowati, 2018). Kinerja adalah hasil kerja baik secara kualitas maupun kuantitas yang dicapai oleh seseorang dalam melaksanakan tugas sesuai tanggung jawab yang diberikan (Mangkunegara, 2016). 


\section{Tabel 1 \\ Hasil Penilaian Kinerja \\ Personil Reskrim \\ Polresta Banjarmasin}

\begin{tabular}{lccccc}
\hline \multirow{2}{*}{$\begin{array}{l}\text { Tahu } \\
\mathrm{n}\end{array}$} & $\begin{array}{c}\text { Sanga } \\
\text { t baik }\end{array}$ & $\begin{array}{c}\text { bai } \\
\mathrm{k}\end{array}$ & $\begin{array}{c}\text { Tida } \\
\mathrm{k} \\
\text { baik }\end{array}$ & $\begin{array}{c}\text { Sanga } \\
\text { t tidak } \\
\text { baik }\end{array}$ & $\begin{array}{l}\text { Jumlah } \\
\text { anggot } \\
\text { a }\end{array}$ \\
\hline 2018 & 13 & 34 & 8 & 5 & 60 \\
\hline 2019 & 10 & 28 & 14 & 8 & 60 \\
\hline
\end{tabular}

Sumber: Polrersta Banjarmasin

Berdasarkan tabel dapat dilihat hasil rekapitulasi penilaian kinerja anggota selama 2 (dua) tahun terakhir terhitung mulai tahun 2018 dan tahun 2019. Bahwa kinerja anggota Personil Reskrim Polresta Banjarmasin mengalami kenaikan dari tahun 2018 kemudian di tahun 2019 terjadi penurunan. Penurunan kinerja tersebut mengindikasikan adanya permasalahan pada kinerja anggota yang menyebabkan penurunan kinerja anggota.

Bekerja dan berpikir memerlukan tingkat intelektual yang tinggi. Cepat lambatnya pemecahan suatu masalah tergantung pada kemampuan intelegensinya. Dilihat dari intelektualnyanya, kita dapat mengatakan cerdas, berakal, dan berpikiran jernih berdasarkan ilmu pengetahuan, yang mempunyai kecerdasan tinggi terutama yg menyangkut pemikiran dan pemahaman.

Selain itu motivasi juga merupakan variabel yang penting dan mempengaruhi kinerja. Motivasi berhubungan langsung dengan kinerja karyawan (Wenty, 2015). Motivasi dapat dipastikan mempengaruhi kinerja, walaupun bukan satu-satunya faktor yang membentuk kinerja (Wibowo, 2011); (Wenty, 2015); (Subariyanti, 2017). Dengan demikian harapan akan menjadi daya penggerak yang memotivasi semangat kerja. Jika harapan menjadi kenyataan maka karyawan cenderung akan meningkatkan kinerja begitu pula sebaliknya.

\section{Studi Literatur}

Kinerja

Menurut Wibowo (2016) kinerja merupakan hasil pekerjaan yang mempunyai hubungan kuat dengan tujuan strategis organisasi, kepuasan konsumen dan memberikan kontribusi pada ekonomi. Kinerja juga dapat dikatakan sebagai suatu hasil yang dicapai dari pekerjaan. Kinerja adalah tentang apa yang dikerjakan dan bagaimana cara mengerjakannya.

Kecerdasan Emosional

$$
\text { Melandy dan Aziza }
$$

kecerdasan emosional adalah kecerdasan untuk menggunakan emosi sesuai dengan keinginan, kemampuan untuk mengendalikan emosi sehingga memberikan dampak yang positif. Kecerdasan emosional dapat membantu membangun hubungan dalam menuju kebahagiaan dan kesejahteraan.

Kecerdasan Intelektual

Intellectual Ability atau Kemampuan Intelektual adalah kapasitas untuk melakukan aktivitas mental (Robbins, 2003). Sebagai contoh, test Intelligence Quotient (IQ) dirancang untuk memastikan kemampuan intelektual umum seseorang. Terdapat tujuh dimensi kemampuan intelektual, yaitu Number aptitude, Verbal comprehension, Perceptual speed, Inductive reasoning, Spatial visualization, dan Memory.

Motivasi

Motivasi adalah daya pendorong yang mengakibatkan seseorang atau keseluruhan bawahan mau dan rela mengerahkan kemampuan, keahlian, dan waktu untuk mengerjakan tugas yang menjadi tanggung jawabnya dalam rangka mencapai tujuan dan sasaran organisasi yang telah ditetapkan (Hafied, 2016) 


\section{Metode Penelitian}

Ruang Lingkup dan Jenis Penelitian

Penelitian menggunakan metode ekspalanasi dengan teknik survey. Metode ini digunakan untuk menganalisis hubungan antara kecerdasan emosional, kecerdasan intelektual, dan motivasi kerja terhadap kinerja Personil Reskrim Polresta Banjarmasin. Penelitian ini menganalisis pengaruh kecerdasan emosional dan kecerdasan intelektual terhadap kinerja Personil Reskrim Polresta Banjarmasin. Kecerdasan emosional, kecerdasan intelektual, motivasi kerja, dan kinerja Personil Reskrim Polresta Banjarmasin termasuk ruang lingkup penelitian ini Manajemen Sumber Daya Manusia. Data penelitian ini adalah data kuantitatif. Data penelitian ini merupakan data primer dan sekunder. Data primer adalah data yang diperoleh langsung kepada sumber data melalui observasi, wawancara, dan penyebaran kuisioner (Iskandar, 2010). Data penelitian adalah data primer dan data sekunder. Data kecerdasan emsosional dan kecerdasan intelektual adalah data primer. Data kinerja adalah data sekunder.

\section{Populasi dan Sampel Penelitian}

Populasi penelitian ini adalah semua anggota Reskrim Polresta Banjarmasin. Polisi yang bertugas pada Reskrim Polresta Banjarmasin berjumlah 60 orang. Menurut Sugiyono (2015) "sampel penelitian adalah bagian dari jumlah dan karakteristik yang dimiliki oleh populasi tersebut." Teknik pengambilan sampel penelitian ini menggunakan sensus. Semua populasi penelitian ini berjumlah 60 orang dijadikan sampel penelitian. Jadi sampel penelitian ini berjumlah 60 orang personil polisi yang bertugas di Reskrim Polresta Banjarmasin.

Teknik Analisa Data

1. Analisis Regresi Linier Berganda Analisis regresi berganda adalah suatu alat analisis peramalan nilai pengaruh dua variabel atau bebas atau lebih terhadap variabel terikat untuk membuktikan ada atau tidaknya hubungan fungsi atau kausal antara dua variabel bebas atau lebih dengan satu variabel terikat (Natawira dan Riduan, 2010). Analisis regresi berganda merupakan perluasan dari regrersi sederhana yaitu dengan menambah jumlah variabel bebas (regresi berganda) (Sanusi, 2012).

2. Uji Asumsi Klasik

Untuk uji asumsi terdiri dari beberapa analisis yaitu uji normalitas, heteroskedastisitas, multikolinieritas, dan pengujian hipotesis.

\section{Hasil Penelitian Dan Pembahasan}

Hasil Uji Asumsi

1. Normalitas Data

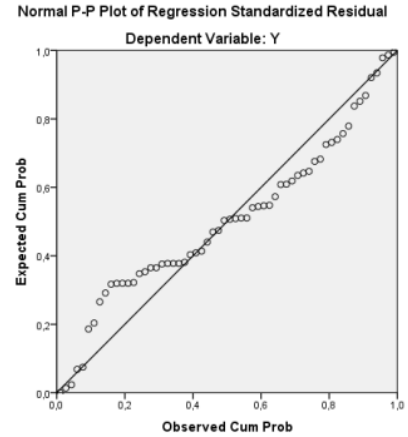

Hasil analisis regresi penelitian ini menunjukkan P-P Plot residual standar regresi. Jika titik-titik pada P-P Plot mengikuti garis lurus data berdistribusi normal. Titik-titik pada P-P Plot hasil 
analisis regresi dalam penelitian ini mengikuti garis lurus sehingga diputuskan data berdistribusi normal

2. Heteroskedastisitas

Heterokedastisitas dapat diuji dengan mudah melalui diagram pancar. Jika dalam diagram ini titik-titik tidak membentuk pola tertentu, maka data penelitian dinyatakan tidak mengalami heterokedatisitas. Titik-titik pada diagram pancar hasil uji heterokedastisitas kecerdasan emosional, kecerdasan intelektual, dan motivasi yang disajikan sebagai berikut:

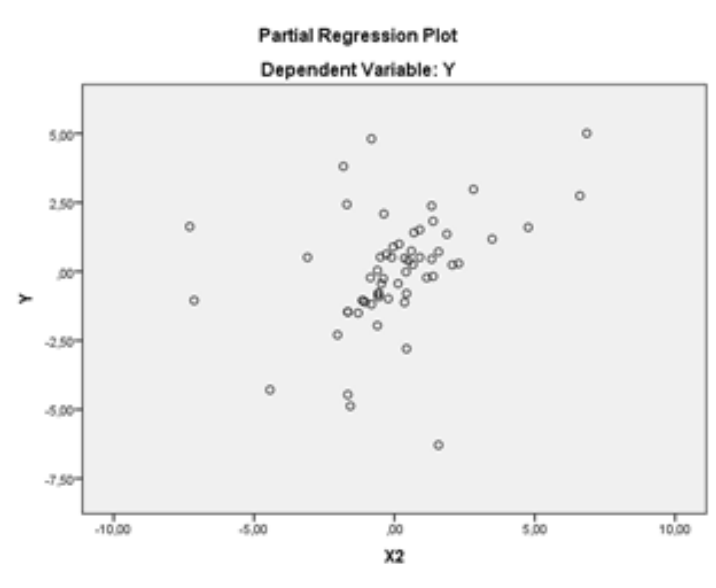

Gambar

Hasil Uji Heteroskedastisitas

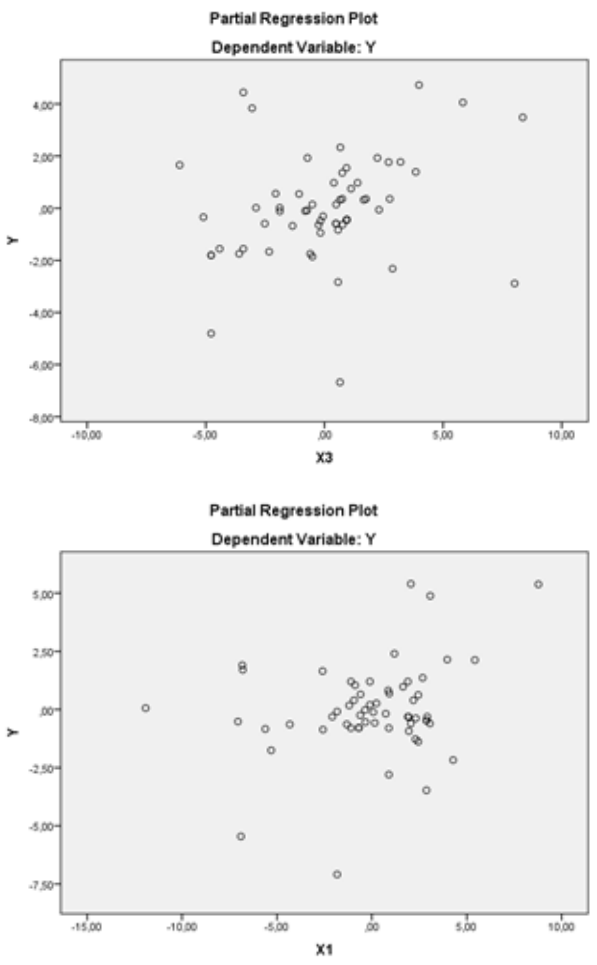

3. Multikolinearitas

Tabel 2

Tolerance dan VIF

\begin{tabular}{clcc}
\hline No. & \multicolumn{1}{c}{ Variabel } & Tolerance & VIF \\
\hline 1 & $\begin{array}{l}\text { Kecerdasan } \\
\text { emosional }\end{array}$ & 0,322 & 3,105 \\
\hline 2 & $\begin{array}{l}\text { Kecedasan } \\
\text { Intelektual }\end{array}$ & 0,307 & 3,261 \\
\hline 3 & Motivasi Kerja & 0,566 & 1,767 \\
\hline \multicolumn{3}{c}{ Multikolinieritas } & dapat ditentukan
\end{tabular}

Multikolinieritas dapat ditentukan dengan menggunakan kriteria tolerance dan VIF. Jika tolerance $>1$ dan VIF < 10 maka data dikatakan tidak mengalami heterokedastisitas. Nilai tolerance tolerance kecerdasan emosional 0,322 , nilai tolerance kecerdasan intelektual 0,307, dan nlai tolerance motivasi kerja 0,566. Nlai tolerance kecerdasan emosional, kecerdasan intelektual, dan motivasi kerja < 1. Nilai VIF kecerdasan emosional 3,105, nilai VIF kecerdasan intelektual 3,261, dan nilai VIF motivasi kerja 1,767. Nilai VIF kecerdaan emosional, kecerdasan intelektual, dan motivasi kerja $<10$. Jadi kecerdasan emosional, kecerdasan 
intelektual, dan motivasi kerja tidak mengalami multikolieritas.

4. Hasil Analisis Regresi

Hasil analisis regresi ditunjukkan dengan tabel koefisien determinnan, koefisien regresi, dan anova.

Tabel 2

Koefisien Determinan

\begin{tabular}{|c|c|c|}
\hline No. & $\begin{array}{c}\text { Koefisien } \\
\text { determinan }\end{array}$ & Nilai \\
\hline 1. & $\mathrm{R}$ & 0,820 \\
\hline 2. & $\mathrm{R}$ square & 0,762 \\
\hline
\end{tabular}

Persentase pengaruh kecerdasan emosi, kecerdasan intelektual, motivasi kerja, dan motivasi kerja terhadap kinerja Personil Reskrim Polresta Banjarmasin diprediksi dengan koefisien determinan (R2). Nilai R2 sebesar 0,762 diperoleh dari nilai $\mathrm{R}$ sebesar 0,9720 yang dikuadratkan. Persentase pengaruh kecerdasan emosi, kecerdasan intelektual, motivasi kerja, dan motivasi kerja terhadap kinerja diperoleh dari perhitungan R2 sebesar $0,762 \times 100 \%=76,2 \%$. Dengan demikian kecerdasan emosi, kecerdasan intelektual, motivasi kerja, dan motivasi kerja mempengaruhi kinerja sebesar $76,2 \%$. Sisanya $23,8 \%$ dipengaruhi variabel selain kecerdasan emosi, kecerdasan intelektual, dan motivasi kerja.

Tabel 3

Koefisien Regresi

\begin{tabular}{|c|c|c|c|c|c|}
\hline No & Variabel & beta & $\mathrm{t}$ & sig & Konstanta \\
\hline 1 & $\mathrm{X} 1-\mathrm{Y}$ & 0,158 & 2,124 & 0,038 & \multirow{3}{*}{$-1,584$} \\
\hline 2 & $X 2-Y$ & 0,325 & 2,980 & 0,004 & \\
\hline 3 & $\mathrm{X} 3-\mathrm{Y}$ & 0,184 & 2,074 & 0,043 & \\
\hline
\end{tabular}

Pengaruh parsial kecerdasan emosi, kecerdasan intelektual, dan motivasi kerja terhadap kinerja Personil Reskrim Polresta Banjarmasin diprediksi dengan menggunakan tabel keisien regresi di atas. Jika signifikan < 0,05, maka hipotesis yang menyebutkan pengaruh kecerdasan emosi, kecerdasan intelektual, dan motivasi kerja terhadap kinerja Personil Reskrim Polresta Banjarmasin secara parsial diterima. Sebaliknya jika signifikan $>0,05$ maka pengaruh kecerdasan emosi, kecerdasan intelektual, dan motivasi kerja terhadap kinerja Personil Reskrim Polresta Banjarmasin tidak diterima.

Signifikansi pengaruh kecerdasan emosi terhadap kinerja Personil Reskrim Polresta Banjarmasin 0,038 < 0,05 . Hipotesis yang menyebutkan kecerdasan emosi berpengaruh signifikan terhadap kinerja Personil Reskrim Polresta Banjarmasin diterima. Signifikansi pengaruh kecerdasan intelektual terhadap kinerja Personil Reskrim Polresta Banjarmasin $0,004<0,05$. Kecerdasan intelektual berpengaruh signifikan terhadap kinerja Personil Reskrim Polresta Banjarmasin diterima. Signifikansi pengaruh motivasi kerja terhadap kinerja Personil Reskrim Polresta Banjarmasin 0,043<0,000. Hipotesis yang menyatakan motivasi kerja berpengaruh signifikan terhadap kinerja Personil Reskrim Polresta Banjarmasin diterima. Persamaan regresi pengaruh kecerdasan emosi, kecerdasan intelektual, dan motivasi kerja terhadap kinerja Personil Reskrim Polresta Banjarmasin:

$$
Y=-1,584+2,124 X 1+2,980 X 2+2,074 X 3+e
$$

Persamaan regresi tersebut dapat dipakai untuk menjelaskan peningkatan kecerdasan emosi, kecerdasan intelektual, dan motivasi kerja diikuti dengan peningkatan kinerja personil Reskrim Polresta Banjarmasin. Peningkatan ini dijelaskan sebagai berikut.

a. Jika variabel lainnya konstan, kecerdasan emsoional meningkat 
satu satuan maka diiringi peningkatan kinerja polisi ini sebesar 2,12.

b. Jika variabel lainnya konstan, kecerdasan intelektual meningkat satu satuan, maka diiringi peningkatan kinerja polisi ini sebesar 2,980.

c. Jika variabel lainnya konstan, motivasi kerja meningkat satu satuan akan diiringi peningkatan kinerja polisi ini sebesar 2,074.

\section{Tabel 4}

Koefisien Regresi

\begin{tabular}{rrrrrr}
\hline \multicolumn{1}{c}{ df } & $\begin{array}{c}\text { Mean } \\
\text { Square }\end{array}$ & $\begin{array}{c}\text { F } \\
\text { Hitung }\end{array}$ & $\begin{array}{c}\text { F } \\
\text { Tabel }\end{array}$ & $\begin{array}{c}\text { Sig. } \\
\text { Hitung }\end{array}$ & $\begin{array}{c}\text { Sig. } \\
\text { Standar }\end{array}$ \\
\hline df-3 & 149,656 & 38,324 & 0,276 & 0,000 & 0,05 \\
\hline df-56 & 3,905 & & & & \\
\hline 59 & & & & & \\
\hline
\end{tabular}

Pengaruh pengaruh kecerdasan emosi, kecerdasan intelektual, dan motivasi kerja terhadap kinerja Personil Reskrim Polresta Banjarmasin secara simultan diprediksi dengan menggunakan uji $\mathrm{F}$ dan signifikansi. Jika F htiug $>\mathrm{F}$ tabel dengan signifikan $<0,05$, maka pengaruh kecerdasan emosi, kecerdasan intelektual, dan motivasi kerja terhadap kinerja Personil Reskrim Polresta Banjarmasin secara simultan diterima. Sebaliknya F htiug < $\mathrm{F}$ tabel dengan signifikan > 0,05, maka pengaruh kecerdasan emosi, kecerdasan intelektual, dan motivasi kerja terhadap kinerja Personil Reskrim Polresta Banjarmasin secara simultan tidak diterima.

Tabel di atas menunjukkan $\mathrm{F}$ hitung 38,324 > F tabel 2,76 dan signifikansi hitung $0,00<0,05$. Ini membuktikan bahwa pengaruh kecerdasan emosional, kecerdasan intelektual, dan motivasi kerja terhadap kinerja Personil Reskrim Polresta Banjarmasin secara simultan diterima.

\section{Kesimpulan}

Berdasarkan hasil pembahasan yang telah dikemukakan di atas, dapat dibuat kesimpulan sebagai berikut:

1. Kecerdasan emosional Personil Reskrim Polresta Banjarmasin termasuk kategori baik. Kecerdasan intelektuaal personil polisi ini baik. Motivasi kerja polisi ini baik. Kinerja polisi ini juga baik.

2. Kecerdasan emosional berpengaruh signifikan terhadap kinerja Personil Reskrim Polresta Banjarmasin. Kecerdasan emsoional meningkat satu satuan maka diiringi peningkatan kinerja polisi ini sebesar 2,12.

3. Kecerdasan intelektual berpengaruh signifikan terhadap kinerja Personil Reskrim Polresta Banjarmasin. Kecerdasan intelektual meningkat satu satuan, maka diiringi peningkatan kinerja polisi ini sebesar 2,980.

4. Motivasi kerja berpengaruh signifikan terhadap kinerja Personil Reskrim Polresta Banjarmasin. Motivasi kerja meningkat satu satuan akan diiringi peningkatan kinerja polisi ini sebesar 2,074 .

5. Kecerdasan emosional, kecerdasan intelektual, dan motivasi kerja berpengaruh signifikan terhadap kinerja Personil Reskrim Polresta Banjarmasin.

\section{DAFTAR PUSTAKA}

Adjma, Djumarno, dan Naskin, 2014. Pengaruh Kecerdasan Emosional, Kecerdasan Intelektal, dan Kecerdasan spritual terhadap Kinerja Karyawan PT Telkom Jakarta Selatan. Jurnal. Online. Diaskses dari Jurnal Manajemen Mutu Volume 13 Nomor 1 Edisi Januari 2014. 
Agustina, T. (2019). Improving Business Performance Through Competitive Advantage: A Study On SMES In Banjarmasin, Indonesia. Eurasia: Economic \& Business, 6(26), 39-59.

Agustina, T., Gerhana, W., \& , S. (2020). The Effect of Locus of Control, Learning, and Adversity Quotient towards Micro Business Success (Study on Entrepreneurship under Foster Group of the Banjarmasin Regional Government). Journal of Wetlands Environmental Management, 8(1), 21. https://doi.org/10.20527/jwem.v8i1.215

Anwar, M. (2017). Pengaruh Motivasi, Kecerdasan Emosional, Dan Kepemimpinan Transformasional Terhadap Kinerja Melalui Kepuasan Kerja .... Dinamika Ekonomi-Jurnal Ekonomi Dan Bisnis, 10(2). Retrieved from https://stienasypb.ac.id/jurnal/index.php/jdeb/article/dow nload/42/34

Anwar, Mahfuzil, Chandrarin, G., Darsono, J. T., \& Respati, H. (2017). Lecturer Job Performance Study: Motivation, Emotional Intelligence, Organizational Culture and Transformational Leadership as Antecedents with Job Satisfaction as an Intervening. IOSR Journal of Business and Management. https://doi.org/10.9790/487x-1906020109

Ardiansyah, Y., \& Sulistiyowati, L. H. (2018). Pengaruh Kompetensi dan Kecerdasan Emosional Terhadap Kinerja Pegawai. Jurnal Inspirasi Bisnis Dan Manajemen, 2(1), 91. https://doi.org/10.33603/jibm.v2i1.1064.

Akimas, Hari Nugroho dan Ahmad Alim Bachri. 2016. Pengaruh Kecerdasan Intelektual (IQ), Kecerdasan Emosional (EQ), Kecerdasan Spiritual (SQ) terhadap Kinerja Pegawai Inspektorat Provinsi
Kalimantan Selatan. Jurnal. Diaskses dari Jurnal Wawasan Manajemen, Vol. 4, Nomor 3, Oktober 2016.

Alma, Buchari.2008. Pengantar Bisnis. Bandung: Alfabeta.

Arikunto, Suharsimi. 2010. Prosedur Penelitian. Jakarta: Rineka Cipta.

Azwar, S. 2012. Pengantar Psikologi Intelegensi, Cetakan Keempat. Yogyakarta: Pustaka Pelajar.

Bahramian, dkk. 2015. Surveying the Relationship of Emotional Intelligence and Staffs' Job Performance Case: Chahar Mahal Bakhtiari Province Gas Company. Jurnal. (Online) diaskes dari American Journal of Educational Research, 2015, Vol. 3 , No. 8 .

Goleman, D. 2001. The Emotionally Intelligent Workplace. San Francisco: Jossey Bass.

Goleman, D. 2002. Emotional IntelligenceKecerdasan Emosional. Jakarta: PT Gramedia Pustaka Utama.

Hafied, Hamzah. 2016. Sumber Daya Manusia. Makasar: Kretakupa.

Iskandar. 2010. Metodologi Penelitian Pendidikan dan Sosial. Jakarta: Gaung Persada

Khairani, Makmun. 2013. Psikologi Umum. Yogyakarta: Asawaja Pressindo.

Kojongian, dkk. 2016. The Influence of Intelligence Quotient and Emotional Quotient Toward Employee Performance (Case Study at PT. Bank Mandiri (Persero) tbk. Manado Branch Office Wanea) Jurnal (Online) diakses dari Jurnal Berkala Ilmiah Efisiensi Volume 16 No. 01 Tahun 2016. 
Kurniawan, Albert. 2014. Metode Riset untuk Ekonomi dan Bisnis. Bandung: Alfabeta.

Lopes, dkk. 2006. Evidence that emotional intelligence is related to job performance and affect and attitudes at work. Jurnal. (online). Diakses dari Psicothema 2006. Vol. 18, supl.

Mangkunegara, Anwar Prabu. 2010. Evaluasi Kinerja SDM, Refika Aditama.Bandung.

Mintowaluto. 2015. Manajemen SDM Masa Depan. Jawa Timur: UPN Veteran.

Misbahuddin dan Iqbal Hasan. 2013. Analisis Data Penelitian dengan Statistik. Jakarta: Bmi Aksara.

Natawiria, A. S. dan Riduwan. 2010. Statistika Bisnis. Bandung: Alfabeta.

Noor, Juliansyah. 2013. Penelitian Ilmu Manajemen. Jakarta : Kencana Prenada Media Group.

Notoatmodjo, Soekidjo. 2009. Pengembangan Sumber Daya Manusia. Jakarta: PT Rineka Cipta.

Nugroho, B. A. 2005. Strategik Jitu Memilih Metode Statistik Penelitian dengan SPSS. Yogyakarta: ANDI.

Olivia, T. 2015. Pengaruh Motivasi Kerja Terhadap Kinerja Karyawan PT. Sejahtera Motor Gemilang. Journal AGORA Vol. 3, No. 2, (2015)

Priansa, Donni Juni. 2014. Perencanaan dan Pengembangan Sumber Daya Manusia. Bandung: Alfabeta.

Pratama, A. Y., \& Suhaeni, T. (2018). Pengaruh Kecerdasan Emosional terhadap Kinerja Karyawan. Jurnal Riset Bisnis Dan Investasi, 3(2), 51. https://doi.org/10.35697/jrbi.v3i2.933
Prawitasari, J. E. (2016). Kecerdasan Emosi. Buletin Psikologi, 6(1), 21-31. https://doi.org/10.22146/bpsi.13280

Purnomo, Sanggit. 2010. Tips Cerdas Emosi dan Spiritual Islami. Jakarta: Kementrian Pendidikan Nasional.

Rahmayanti 2014. Kinerja Karyawan pada CV Putra Kaltim Samarinda. (Jurnal). Diakses dari eJournal Ilmu Administrasi Bisnis, 2014, 2 (2):

Robbin, Stephen. P. 2008. Perilaku Organisasi. Jakarta : Salemba Empat.

Sanusi, Anwar 2012. Metodologi Penelitian Bisnis. Jakarta; Salemba Empat.

Santoso, O. B. dan Ashari. 2005. Analisis Statistik dengan Mozrosoft Excell dan SPSS. Yogyakarta: ANDI.

Sedarmayanti. 2009. Manajemen Sumber daya Manusia.Bandung: PT Refika Aditama.

Subariyanti, H. (2017). Hubungan Motivasi Kerja dan Kepuasan Kerja Terhadap Kinerja Karyawan PTLR Batan. Jurnal Ecodemica, 1(2), 224-232. Retrieved from http://ejournal.bsi.ac.id/ejurnal/index.php/e codemica/article/view/2102/pdf

Sugiyono. 2015. Metode Penelitian Bisnis. Bandung: Alfabeta.

Sunyoto, Danang. 2012. Teori. Kuisioner, dan Analisis Data Sumber Daya Manusia. Yogyakarta: CAPS.

Supramono fdan Intiyas Utami. 2004. Desain Proposal Penelitian Akuntansi dan keuangan Yogyakarta: Andi.

Sutrischastini dan Riyanto. 2015. Pengaruh Motivasi Kerja Terhadap Kinerja Pegawai Kantor Sekretariat Daerah Kabupaten Gunung Kidul. Diakses dari Jurnal Kajian Bisnis Vol. 23, No. 2, 2015, 
Trihandini, M. F. 2005. Analisi Pengaruh Kecerdasan Intelektual, Kecerdasan Emosional dan Kecerdasan Spiritual Terhadap Kinerja Karyawan, Tesis, Fakultas Ekonomi Universitas Diponegoro, Semarang.

Wahab, A., Anwar, M., \& Yasrie, A. (2018). KEPUASAN KERJA MEMEDIASI MOTIVASI DAN KECERDASAN EMOSIONAL TERHADAP KINERJA DOSEN PNS Dpk DAN DOSEN YAYASAN PADA KOPERTIS WILAYAH XI KALIMANTAN (STUDI PADA FE UVAYA, FE UNISKA DAN STIMI BANJARMASIN). Jurnal Ekonomi Dan Bisnis, 11(2), 351-369.
Wenty, C. S. (2015). Hubungan Motivasi Kerja Dengan Kinerja Pegawai Dinas Pendidikan Kabupaten Pesisir Selatan. Jurnal Administrasi Pendidikan, 3(2), 937-942.

Wibowo. 2016. Perilaku dalam Organisasi. Jakarta: Rajawali Press.

Yosep, Iyus. 2005. Pentingya ESQ (Emotional Spiritual Quotion) Bagi Perawat dalam Manajemen Konflik. Tesis. Universitas Padjajaran, Bandung.

Zohar, Danah dan Marshall, Ian, 2007. Kecerdasan Spiritual. Terjemahan Rahmani Astuti, Ahmad Nadjib, Ahmad Baiquni. Bandung L Mizan 